\title{
Nociceptive Primitive Reflexes in Neurologically and Cognitively Healthy Aging Subjects
}

\author{
Cecilia Camarda, Paola Torelli, Carmela Pipia, Delia Azzarello, \\ Iacopo Battaglini, Gianluca Sottile, Giovanna Cilluffo, Rosolino Camarda
}

\begin{abstract}
Background: To assess the prevalence of three nociceptive primitive reflexes (nPR), i.e., glabellar tap, snout reflex, and palmomental reflex, in neurologically and cognitively healthy $(\mathrm{NCH})$ aging subjects. Objective: To investigate whether nPR are crosssectionally associated with white matter hyperintensities (WMH), lacunes, atrophy of the caudate nuclei, and global brain atrophy. Methods: A total of $1246 \mathrm{NCH}$ subjects aged 45-91 years were included in the study and underwent standard brain MRI. Atrophy of the caudate nuclei and global brain atrophy were assessed through the bicaudate ratio ( $\mathrm{BCr}$ ) and lateral ventricles to brain ratio (LVBr), respectively. WMH were assessed through visual rating scales. Lacunes were also rated. Association of nPR with vascular risk factors/ diseases and imaging findings was evaluated using logistic regression analysis. Results: nPR were exhibited by $33.1 \%$ of subjects and increased with age. Subjects with nPR performed less than subjects without nPR in tests evaluating global cognition, executive functions, attention, and language. Snout reflex was the most common nPR, followed by glabellar tap and palmomental reflex. Glabellar tap was associated with parieto-temporal $\mathrm{WMH}, \mathrm{BCr}$, and $\mathrm{LVBr}$; snout reflex was associated with frontal lacunes, temporal $\mathrm{WMH}$, $\mathrm{BCr}$, and LVBr; palmomental reflex was associated with parieto-occipital WMH, basal ganglia lacunes, BCr, and LVBr. Conclusions: This study demonstrates that in $\mathrm{NCH}$ aging individuals, $\mathrm{nPR}$ are associated with $\mathrm{WMH}$, lacunes, $\mathrm{BCr}$, and $\mathrm{LVBr}$ and are probably a warning sign of incipient cognitive decline. Therefore, $\mathrm{NCH}$ subjects presenting nPR should manage their vascular risk factors/vascular diseases rigorously in order to prevent or delay progression of small vessel disease, and future neurological and cognitive disabilities.
\end{abstract}

RÉSUMÉ: Présence de réflexes archaïques nociceptifs chez des sujets âgés en bonne santé sur les plans neurologique et cognitif. Contexte: Évaluer la prévalence de trois réflexes archaïques nociceptifs (RAN) chez des sujets âgés en bonne santé sur les plans neurologique et cognitif : glabellaire, de la moue et palmo-mentonnier. Objectif: Examiner dans quelle mesure ces RAN peuvent être associés de façon transversale à des hyper-signaux de la substance blanche, à des infarctus cérébraux de type lacunaire, à une atrophie du noyau caudé et à une atrophie générale du cerveau. Méthodes: Au total, 1246 sujets dont l'âge variait entre 45 et 91 ans ont été inclus dans cette étude. Fait à noter, ils étaient tous en bonne santé sur les plans neurologique et cognitif. Tous ont été soumis à des examens d'IRM standards. Tant l'atrophie du noyau caudé que celle, générale, du cerveau ont été mesurées respectivement au moyen du ratio double du noyau caudé et du ratio de surface des ventricules latéraux par rapport à la surface du cerveau. Les hypersignaux de la substance blanche ont quant à eux été évalués par l'entremise d'échelles d'évaluation visuelles. La présence d'infarctus cérébraux de type lacunaire a également été mesurée. Enfin, l'association entre, d'une part, des maladies/facteurs de risque vasculaires et les RAN évoqués ci-dessus, et, d'autre part, les résultats obtenus par IRM et ces mêmes RAN, a été évaluée à l'aide d'un modèle de régression logistique. Résultats: Des RAN ont été détectés chez 33,1\% des sujets étudiés et ont eu tendance à devenir plus fréquents avec l'âge. En comparaison avec les sujets exempts de RAN, ceux qui en présentaient les signes ont eu tendance à moins bien performer à divers tests évaluant leur cognition d'ensemble, leurs fonctions exécutives, leur niveau d'attention et leurs habiletés langagières. Le réflexe de la moue s'est avéré le RAN le plus fréquent. Ont suivi ensuite les réflexes glabellaire et palmomentonnier. Fait à noter, le réflexe glabellaire a été associé à des hyper-signaux de la substance blanche au niveau du carrefour temporo-pariétal et à une atrophie dévoilée par le ratio double du noyau caudé et celui de la surface des ventricules latéraux par rapport à la surface du cerveau. Le réflexe de la moue a été associé à des infarctus cérébraux de type lacunaire de la région frontale du cerveau, à des hyper-signaux de la substance blanche au niveau de la région temporale et aussi à une atrophie dévoilée par les deux ratios tout juste mentionnés. Enfin, le réflexe palmo-mentonnier a été associé à des hypersignaux de la substance blanche au niveau du sillon pariéto-occipital, à des infarctus cérébraux de type lacunaire affectant les ganglions de la base ainsi qu'à une atrophie du cerveau, révélée cette fois encore par les deux mêmes ratios. Conclusions: Chez des sujets âgés et en bonne santé sur les plans neurologique et cognitif, cette étude démontre que les RAN sont associés à des hyper-signaux de la substance blanche, à des infarctus cérébraux de type lacunaire et à une augmentation de l'atrophie du cerveau. Ces RAN constituent probablement des signes précurseurs de déclin cognitif. En conséquence, des sujets en bonne santé sur les plans neurologique et cognitif présentant des signes de RAN devraient veiller à prendre en charge de façon rigoureuse leurs facteurs de risque vasculaires afin de prévenir ou de retarder la progression de maladies atteignant leurs petits vaisseaux sanguins, ces maladies pouvant entraîner de possibles déficiences neurologiques et cognitives.

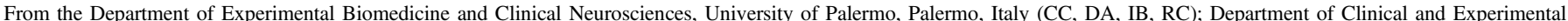

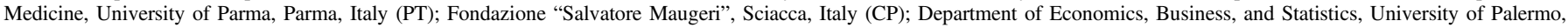
Palermo, Italy (GS); Institute of Biomedicine and Molecular Immunology, National Research Council, Palermo, Italy (GC).

Received September 4, 2018. Final Revisions Submitted November 22, 2018. Date of Acceptance December 3, 2018.

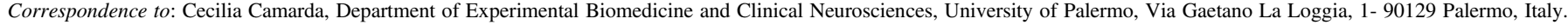
Email: cecilia.camarda@unipa.it 
Keywords: Healthy aging subjects, Nociceptive primitive reflexes, White matter hyperintensities, Lacunes, Caudate atrophy, Global cerebral atrophy

doi: $10.1017 /$ cjn. 2018.388

Can J Neurol Sci. 2019; 46: 199-208

\section{INTRODUCTION}

Primitive reflexes (PR) are a group of stereotyped motor responses mediated by brainstem structures triggered by specific sensory inputs. ${ }^{1}$ PR are found in newborns, disappear after the first year of life, and may be released later in life. PR can be found in Alzheimer's disease (AD) and vascular dementia, ${ }^{2}$ cerebrovascular disease, ${ }^{3}$ Parkinsons's disease, ${ }^{4}$ amyotrophic lateral sclerosis, ${ }^{5}$ other degenerative diseases, ${ }^{6}$ and in healthy aging subjects. ${ }^{7}$ In clinical practice, PR are considered individually of poor diagnostic significance, whereas their various combinations are considered a warning sign of frontal lobe dysfunction. ${ }^{8}$ Whether the reappearance of PR in healthy aging individuals is a consequence of age and/or of the accumulated load of degenerative and vascular lesions is still an open issue.

Tauopathy, $\beta$-amyloidosis (A $\beta)$, and atrophy of frontal, parietal, and temporal cortices are the key elements of the underlying pathophysiology of $\mathrm{AD}$ and Mild Cognitive Impairment (MCI). ${ }^{9}$ These elements also occur in cognitively normal $(\mathrm{CN})$ aging individuals and are nearly inevitable by old age. ${ }^{10}$ Thinning of prefrontal, parietal, and temporal association cortices, cerebellum, and striatum occurs in normal aging. ${ }^{11} \mathrm{In} \mathrm{CN}$ individuals, elevated $\mathrm{A} \beta$ accumulation accelerates cortical atrophy ${ }^{12}$ and is associated with an increased burden of frontal, parietal, and occipital periventricular white matter hyperintensities (WMH$\mathrm{PV}) .{ }^{13} \mathrm{WMH}$ and lacunes, i.e., two of the most common imaging hallmarks of cerebral small vessel disease (SVD), ${ }^{14}$ increase with age, ${ }^{15,16}$ locally disrupt the structural integrity of white matter (WM), and induce thinning of the connected cortical regions through Wallerian degeneration. ${ }^{17,18}$ Cortical atrophy induced by WMH drives, in turn, cognitive decline. ${ }^{19}$ The pattern of cortical atrophy induced by WMH-PV overlaps substantially with the patterns of cortical atrophy age-related and AD-related. ${ }^{20}$

Intact WM connections are necessary for the integration of information within the cerebral networks. Both vascular and atrophic changes occurring in the aging brain fragment over time cerebral networks into disconnected parts, which lead to the loss of the functional inter-relationships among cortical regions, and between them and subcortical structures. Therefore, it seems reasonable to suspect that the re-appearance of PR in healthy aging individuals may be the consequence of the loss of the brainstem inhibition due to the vascular and/or atrophic damage of the dedicated cerebral networks. Considering that extensive circuits interconnect cortex, basal ganglia (BG), thalamus, cerebellum, and brainstem, ${ }^{21,22}$ we hypothesized that global cerebral atrophy and atrophy of the caudate nuclei could also be related to the presentation of PR.

The aims of this cross-sectional study on a large sample of neurologically and cognitively healthy $(\mathrm{NCH})$ adult-to-oldest old subjects are: 1) to evaluate whether PR are associated with $\mathrm{WMH}$, lacunes, and with two linear measures of caudate atrophy and overall cerebral atrophy, i.e., bicaudate ratio $(\mathrm{BCr})$ and lateral ventricles to brain ratio ( $\mathrm{LVBr}$ ), respectively; 2) to evaluate the relationship between $\mathrm{PR}$ and the topographical location of imaging-detected cerebrovascular lesions. In this paper, the terms "adult", "elderly", "old", and "oldest old" are used to indicate people aged $45-64,65-74,75-84$, and $\geq 85$ years, respectively.

\section{Methods \\ Participants}

Data were used from the Cognitive Impairment through Aging (CogItA) study, a hospital-based prospective study focused on normal and pathological aging beginning on January 2, 2000 and closing on December 30, 2015. Participants in the study were outpatients self-referred or referred by general practitioners for health screening to the clinics, including the memory clinic, of the Department of Neurology and Cognitive Disorders of the teaching Hospital (AOUP "P. Giaccone") of the School of Medicine of the University of Palermo, Italy. Details of the inclusion and exclusion criteria of the CogItA study can be found elsewhere. ${ }^{23}$ The local Ethics Committee approved the study, and all participants provided written informed consent.

Data of CogItA NCH participants aged 45-91 years were used. These subjects did not complain about cognitive concerns as corroborated by the informants, showed normal global cognition at the Mini-Mental State Examination, ${ }^{24}$ no impairment in the domains of memory, attention, executive functions, language, and constructional and visuospatial skills, and normal scores on the Activities of Daily Living (ADL) $)^{25}$ and Instrumental Activities of Daily Living (IADL) ${ }^{26}$ scales. Moreover, they scored a 0 on the Clinical Dementia Rating (CDR) scale $^{27}$ and did not convert to MCI or dementia during follow-up (mean follow-up = $79.15 \pm 33.54$ months).

\section{Baseline Clinical Assessment}

Clinical assessment included medical history, neurological, neuropsychological, and behavioral examinations, as well as blood tests, carotid ultrasonography, and brain imaging. The vascular risk factors (VRF) evaluated were cigarette smoking, arterial hypertension, diabetes mellitus, hypercholesterolemia, hypertriglyceridemia, obesity (Body Mass Index $[\mathrm{BMI}] \geq 30 \mathrm{Kg} / \mathrm{m}^{2}$ ), and chronic obstructive pulmonary disease (COPD). The vascular diseases (VD) evaluated were ischaemic heart diseases, atrial fibrillation, cardiac valvulopathies, chronic heart failure, history of transient ischemic attacks, and lower limb arteriopathy. VRF and VD were assessed as reported elsewhere. ${ }^{23}$ APOE genotypes were assessed using standard methods ${ }^{28}$ on $94.2 \%(n=1174)$ of the sample. Subjects with at least 1 APOE $\varepsilon 4$ allele were considered as APOE $\varepsilon 4$ carriers. 


\section{Neurological Examination}

$\mathrm{NCH}$ participants underwent a standardized neurological examination including a careful evaluation of PR. Although many PR are recognized, we focused on three nociceptive PR $(\mathrm{nPR})$, i.e., glabellar tap, snout reflex, and palmomental reflex frequently observed in normal adults, and aging subjects. ${ }^{7,8}$ Examination of nPR was performed independently by two neurologists blinded to the patients history and neuroimaging. Each reflex was considered present according to a combined decision, and only when a reproducible reaction was obtained.

\section{Functional and Behavioral Assessments}

Functional status was assessed using the $\mathrm{ADL},{ }^{25}$ and the IADL $^{26}$ scales administered to the informants, and somatic multimorbidity was quantified through the Cumulative Illness Rating Scale (CIRS). ${ }^{29}$ Depressive symptoms were evaluated using the Cornell Scale for Depression ${ }^{30}$ and the depression subscale of the Hospital Anxiety and Depression Scale. ${ }^{31}$ Anxiety symptoms were evaluated through the anxiety subscale of the Hospital Anxiety and Depression Scale ${ }^{31}$ and the Hamilton Anxiety Rating Scale. ${ }^{32}$ Depression and anxiety were deemed to be present if at least one of the depression and anxiety scores was found to be above the cut-off level.

\section{Neuropsychological Assessment}

The neuropsychological assessment included the Mini-Mental State Examination ${ }^{23}$ as a test of global cognition and a neuropsychological battery of 12 tests covering 6 cognitive domains, i.e., memory, attention, executive function, language, constructional ability, and visuospatial skill, as previously described. ${ }^{33}$

\section{Carotid Ultrasonography and Imaging Assessments}

Intimal-medial thickness (IMT) and stenosis of internal carotid arteries (SICA) were assessed as reported elsewhere. ${ }^{23}$ Participants were scanned on a 1.5T system (Signa HDxt; GE Medical System, Milwaukee, Wisconsin, USA). Details of the protocol employed can be found elsewhere. ${ }^{23}$ MR images included T1-w and $\mathrm{T} 2-\mathrm{w}$, and fluid-attenuated inversion recovery (FLAIR) sequences and were recorded and analyzed over time by the Radiology Department of the teaching Hospital affiliated to the School of Medicine of the University. However, for the purpose of the present study, brain scans were re-evaluated independently by two neurologists (CC and IB) trained in neuroimaging and blinded to subjects data. Caudate atrophy, global cerebral atrophy, $\mathrm{WMH}$, and lacunes were evaluated. The $\mathrm{BCr}$ and the $\mathrm{LVBr}$ were calculated as reported elsewhere. ${ }^{23} \mathrm{WMH}$ and lacunes were evaluated according to published criteria. ${ }^{34} \mathrm{WMH}$ were assessed according to the Wahlund scale. ${ }^{35}$ To measure WMH severity, the scores of frontal, parieto-occipital, temporal, infratentorial, and basal ganglia regions of both hemispheres were summed in order to obtain the partial score of deep/subcortical WMH (WMH-SC) (range 0-18), of the infratentorial WMH (WMHINF) (range 0-6), of the basal ganglia WMH (WMH-BG) (range $0-6$ ), and the WMH total score (WMH-T) (range 0-30). Lobes were distinguished according to anatomical landmarks. Since the Wahlund scale does not evaluate WMH-PV, we also used the Fazekas scale. ${ }^{36}$ WMH-PV severity was graded as mild, moderate, and severe and scored 1, 2, and 3, respectively. WMH-PV scores were dichotomized as $0-1$ vs $2-3$. Lacunes were identified on $\mathrm{T}-2 \mathrm{w}$ images and scored topographically according to the Whalund regions used to score WMH. Lacunes were categorized as lacunes-SC, lacunes-INF, lacunes-BG, and lacunes-T and were recorded into a binary variable with two levels: the absence of lacunes $=0$ and the presence of at least 1 lacuna $=1$. Interrater reliability for the assessment of $\mathrm{BCr}, \mathrm{LVBr}$, $\mathrm{WMH}$, and lacunes in random samples was excellent.

\section{Statistical Analysis}

Descriptive statistics were used. Continuous variables were compared between nPR using one-way analysis of variance. Differences of categorical variables between nPR were analyzed using $\chi^{2}$ test. Results were summarized as absolute numbers with percentages, mean and SD, median, and IQR. The association between putative risk factors/diseases, imaging-detected lesions, and nPR was assessed using logistic regression models with adjustments for age, sex, and education (years). The full model (Model 1) included all the variables resulted significant in the univariate analysis. Parsimonious models were obtained using a stepwise approach, and the Akaike information criterion ${ }^{37}$ was used to select the reduced model (Model 2). Logistic regression models were also used to evaluate the association of glabellar tap, snout reflex, and palmomental reflex with $\mathrm{BCr}, \mathrm{LVBr}$, and the topographical locations of lacunes and WMH evaluated according to the Wahlund scale. By using tetrachoric correlation, ${ }^{38}$ we found that depression and anxiety were strongly correlated $(\rho=1$; $p<0.001$ ). By using the Pearson's correlation test, we also found that $\mathrm{BCr}$ and $\mathrm{LVBr}$ were highly correlated $(\rho=0.93, p<0.001)$. Therefore, due to multicollinearity problems, association of depression, anxiety, $\mathrm{BCr}$, and $\mathrm{LVBr}$ with $\mathrm{nPR}$, and association of $\mathrm{BCr}$ and $\mathrm{LVBr}$ with individual $\mathrm{nPR}$ were estimated using logistic regression analysis separately with adjustments for age, sex, and education (years). Results are presented as odd ratio with $95 \%$ confidence interval $(95 \% \mathrm{CI})$. Level of significance was set at $p \leq 0.05$. All analyses were performed using R (3.4.1) statistical software.

\section{Results}

The frequency of nPR was computed on $1246 \mathrm{NCH}$ subjects aged 45-91 years (Table 1). Overall, 33.1\% $(n=413)$ of all subjects showed at least one nPR. Glabellar tap, snout reflex, and palmomental reflex were present in all age classes and progressively increased with age showing the highest frequency in the oldest old individuals. The snout reflex was the nPR with the highest frequency (23.5\%), followed by glabellar tap (15.7\%) and palmomental reflex (5.9\%). With the progressive increase of age, nPR were seen in various combinations, particularly in the old and oldest old subjects. Given that the latter were few, subsequent analysis was conducted pooling together the old and oldest old classes in the class of old-oldest old. According to the presence of at least one $\mathrm{nPR}$, subjects were subdivided into those having at least one $\mathrm{nPR}(\mathrm{nPR}+, n=413)$, and those without $\mathrm{nPR}(\mathrm{nPR}-$, $n=833$ ). Baseline characteristics of $\mathrm{NCH}$ subjects with and without nPR are shown in Table 2 . Females significantly outnumbered males in both groups, particularly in the nPR-group. 
Table 1: Number and types of nociceptive primitive reflexes (nPR) according to age classes

\begin{tabular}{|c|c|c|c|c|c|}
\hline & \multicolumn{5}{|c|}{ Age classes (years) } \\
\hline & $45-64$ & $65-74$ & $75-84$ & $85-91$ & All ages \\
\hline & $n=847(68.0)$ & $n=283$ & $n=108(8.7)$ & $n=8(0.6)$ & $n=1.246$ \\
\hline No nPR & $691(81.6)$ & $121(42.8)$ & $21(19.4)$ & $0(0.0)$ & $833(66.9)$ \\
\hline One nPR & $128(15.1)$ & $114(40.3)$ & $43(39.8)$ & $0(0.0)$ & $285(22.9)$ \\
\hline Two nPR & $27(3.2)$ & $44(15.5)$ & $34(31.5)$ & $4(50.0)$ & $109(8.8)$ \\
\hline Three nPR & $1(0.1)$ & $4(1.4)$ & $10(9.3)$ & $4(50.0)$ & $19(1.5)$ \\
\hline Glabellar tap & $95(60.9)$ & $62(38.3)$ & $32(36.8)$ & $6(75.0)$ & $195(47.2)$ \\
\hline Snout reflex & $76(48.7)$ & $131(80.7)$ & $78(89.7)$ & $8(100.0)$ & $293(70.9)$ \\
\hline Palmomental reflex & $14(9.0)$ & $21(13.0)$ & $31(35.6)$ & $6(75.0)$ & $72(17.4)$ \\
\hline
\end{tabular}

Data presented are number $(\%)$.

Compared to subjects nPR-, subjects nPR+ were significantly older and more educated and showed worse functional scores, and higher CIRS comorbidity and severity indexes. Former and current smokers were significantly more common within subjects nPR+. Compared to subjects nPR-, subjects nPR+ showed significant higher frequency of almost all VRF and VD evaluated, suggesting a higher vascular burden in the latter group than in the former. Subjects nPR + were significantly more APOE $\varepsilon 4$ carriers than subjects nPR-. All subjects performed well above age- and education-corrected cut-offs for cognitive normality (Table 3). However, subjects nPR+ performed less in tests evaluating global cognition, executive functions, attention, and language. Depressive and anxiety symptoms were significantly more frequent in subjects nPR+ than in subjects nPR-. IMT and SICA were more frequent in subjects $n P R+$ than in subjects nPR-. $\mathrm{WMH}$ and lacunes were highly frequent in subjects nPR+ compared to subjects nPR-. BCr and $\mathrm{LVBr}$ were significantly higher in subjects nPR+ than in subjects nPR- (Table 4). Because $\mathrm{nPR}$ increase with age as many of the factors associated with nPR do, we stratified these factors according to age classes. Table $\mathrm{S} 1$ in the supplementary material shows all the variables resulted significant in the univariate analysis of $\mathrm{NCH}$ subjects with and without nPR according to age classes. The factors that increased with increasing age were WMH-PV, WMH-BG, depression, anxiety, $\mathrm{BCr}$, and $\mathrm{LVBr}$. Therefore, in subsequent analyses, age was entered into all statistical models to account for this confound.

The association between nPR and VRF, VD, carotid ultrasonography findings, WMH, lacunes, APOE $\varepsilon 4$ carriers, depression, anxiety, $\mathrm{BCr}$, and $\mathrm{LVBr}$, was evaluated through logistic regression models (Table 5). At Model 2 (reduced), APOE $\varepsilon 4$ allele, WMH-SC, WMH-PV, lacunes-SC, depression, anxiety, $\mathrm{BCr}$, and $\mathrm{LVBr}$ were significantly associated with $\mathrm{nPR}$. When analyzing the association of each $\mathrm{nPR}$ with $\mathrm{BCr}, \mathrm{LVBr}$, and the topographical location of lacunes and WMH scored according to the Wahlund scale (Table 6), at Model 2, the risk of glabellar tap resulted related to $\mathrm{BCr}, \mathrm{LVBr}$, and frontal, parieto-occipital, and temporal WMH. The risk of snout reflex resulted related to frontal lacunes, temporal $\mathrm{WMH}, \mathrm{BCr}$, and $\mathrm{LVBr}$. The risk of palmomental reflex resulted related to parieto-occipital $\mathrm{WMH}$, basal ganglia lacunes, $\mathrm{BCr}$, and $\mathrm{LVBr}$.

\section{Discussion}

Glabellar tap, snout reflex, and palmomental reflex are frequently observed in $\mathrm{NCH}$ adult, elderly, and old-oldest old subjects and increase with age either in isolation or in combination. VRF, VD, and CIRS comorbidity and severity indexes, APOE $\varepsilon 4$ carriers, imaging-detected cerebrovascular lesions, IMT, and SICA were significant more frequent among subjects $n P R+$ than subjects nPR-. The cognitive normality of our participants supports previous conclusion that the presence of $\mathrm{nPR}$ is unrelated to cognition. ${ }^{39}$ However, the fact that $\mathrm{NCH}$ subjects $\mathrm{nPR}+$ performed less in tests evaluating global cognition, executive function, attention, and language than those nPR- suggests that the presentation later in life of nPR may precede any evidence of cognitive impairment.

The association of nPR with WMH and lacunes is not surprising, given that these two hallmarks of cerebral SVD are frequently observed in healthy aging individuals ${ }^{14,15}$ and are associated with nPR and other neurological abnormalities. ${ }^{23,40}$ The association of $\mathrm{nPR}$ with $\mathrm{BCr}$ and $\mathrm{LVBr}$ in adult-to-oldest old subjects deserves, instead, some considerations. $\mathrm{BCr}$ is considered a reliable marker of caudate atrophy in normal aging. ${ }^{41}$ It may be that in our cohort, the increased intercaudate distance was the consequence of the age-related shrinkage of the striatum, ${ }^{11}$ or of the basal ganglia lacunes, or of the degeneration of corticostriatal connections secondary to the cortical thinning induced by frontal lacunes and frontal, parietal, and temporal WMH-SC, or by WMH-PV, or by the cortical $\mathrm{A} \beta$ deposition. Considering that age and APOE $\varepsilon 4$ allele increase the risk of $\mathrm{A} \beta$ deposition in $\mathrm{CN}$ individuals, ${ }^{10}$ that the majority of subjects $\mathrm{nPR}+(62 \% ; n=257)$ were elderly-to-oldest old, and that the presence of APOE $\varepsilon 4$ allele increased of about $73 \%$ the risk of having nPR, it is reasonable to suspect that the subjects $\mathrm{nPR}+$ were in high percentage amyloid positive. The strong association of WMHPV with nPR is likely to reflect the disruption of long associating tracts induced by WMH-PV and the consequent thinning of frontal, parietal, and temporal association cortices. ${ }^{18-20}$ One of these tracts could be the superior longitudinal fasciculus (SLF). SLF is a long associating tract, which runs near the lateral ventricles, interconnects bidirectionally prefrontal and premotor frontal cortices and parietal, temporal, and occipital association 
Table 2: Baseline characteristics of adult-to-oldest old NCH subjects $(n=1246)$ with and without nociceptive primitive reflexes (nPR)

\begin{tabular}{|c|c|c|c|c|}
\hline & nPR + & nPR - & Statistics & $P$ Value \\
\hline & $n=413(33.2)$ & $n=833(66.8)$ & $F$ test or $\chi^{2}$ & \\
\hline Sex (female) & $256(62.0)$ & $587(70.5)$ & 8.70 & 0.003 \\
\hline Age (years) & $67.0 \pm 9.9$ & $55.1 \pm 8.8$ & 470.49 & $<0.001$ \\
\hline Education (years) & $9.0 \pm 4.3$ & $8.0 \pm 5.1$ & 12.61 & $<0.001$ \\
\hline \multicolumn{5}{|l|}{ Functional assessment } \\
\hline Activities of Daily Living (f.l.) & $0.2 \pm 0.5$ & $0.1 \pm 0.3$ & 38.02 & $<0.001$ \\
\hline $\begin{array}{l}\text { Instrumental Activities of Daily } \\
\text { Living (f.l.) }\end{array}$ & $0.2 \pm 0.5$ & $0.1 \pm 0.4$ & 21.59 & $<0.001$ \\
\hline \multicolumn{5}{|l|}{$\begin{array}{l}\text { Cumulative Illness Rating Scale } \\
\text { (CIRS) }\end{array}$} \\
\hline Comorbidity index & $21.7 \pm 3.2$ & $20.3 \pm 3.0$ & 60.59 & $<0.001$ \\
\hline Severity index & $2.5 \pm 1.5$ & $1.9 \pm 1.3$ & 44.12 & $<0.001$ \\
\hline \multicolumn{5}{|l|}{ Vascular risk factors } \\
\hline Former smoking & $55(13.4)$ & $77(9.3)$ & \multirow[t]{2}{*}{7.86} & \multirow[t]{2}{*}{0.020} \\
\hline Current smoking & $110(26.8)$ & $195(23.5)$ & & \\
\hline Arterial hypertension & $265(64.2)$ & $345(41.4)$ & 56.27 & $<0.001$ \\
\hline Diabetes mellitus & 85 (20.6) & $122(14.6)$ & 6.60 & 0.010 \\
\hline Hypercholesterolemia & $193(46.7)$ & $376(45.2)$ & 0.21 & 0.651 \\
\hline Hypertriglyceridemia & $87(21.1)$ & $153(18.4)$ & 1.10 & 0.293 \\
\hline $\begin{array}{l}\text { Chronic obstructive pulmonary } \\
\text { disease }\end{array}$ & $25(6.1)$ & $20(2.4)$ & 9.53 & 0.002 \\
\hline $\begin{array}{l}\text { Obesity (Body Mass Index } \geq 30 \\
\mathrm{Kg} / \mathrm{m}^{2} \text { ) }\end{array}$ & $172(42.7)$ & $265(33.5)$ & 9.21 & 0.002 \\
\hline \multicolumn{5}{|l|}{ Vascular diseases } \\
\hline Ischaemic hearth diseases & 48 (11.6) & $40(4.8)$ & 18.54 & $<0.001$ \\
\hline Cardiac valvulopathies & $16(3.9)$ & $18(2.2)$ & 2.44 & 0.118 \\
\hline Atrial fibrillation & $24(5.8)$ & $10(1.2)$ & 20.41 & $<0.001$ \\
\hline Chronic heart failure & $20(4.8)$ & $16(1.9)$ & 7.39 & 0.007 \\
\hline $\begin{array}{l}\text { History of transient ischemic } \\
\text { attacks }\end{array}$ & $39(9.4)$ & $31(3.7)$ & 15.94 & $<0.001$ \\
\hline Lower limb arteriopathy & $10(2.4)$ & $5(0.6)$ & 6.24 & $<0.001$ \\
\hline \multicolumn{5}{|l|}{ Apolipoprotein E (APOE) ${ }^{\mathrm{a}}$} \\
\hline APOE $\varepsilon 4$ carriers & $229(56.1)$ & $171(22.3)$ & \multirow[t]{2}{*}{133.92} & \multirow[t]{2}{*}{$<0.001$} \\
\hline APOE $\varepsilon 4$ non carriers & $179(43.9)$ & $595(77.7)$ & & \\
\hline
\end{tabular}

${ }^{\mathrm{a}}$ Missing data: $\mathrm{nPR}+=5(1.2 \%)$; nPR- $=67(8.7 \%)$.

f.l., functions lost.

Data presented are number (\%) for categorical, and mean (SD) for continuous data.

Bold values indicate significance at $p \leq 0.05$.

cortices, and subserves memory, attention, executive, audiospatial, and visuospatial processing. ${ }^{42}$ The possibility that WMH-PV may have damaged SLF disconnecting the above association cortices could explain why subjects nPR+ performed less than subjects nPR- in tests evaluating global cognition, executive functions, attention, and language. $\mathrm{LVBr}$ was also associated with $\mathrm{nPR}$. LVBr is a measure of ventricular enlargement that is commonly observed in healthy older adults. ${ }^{43}$ Ventricular expansion reflects gray matter (GM) and WM volumetric reduction throughout multiple brain regions, is associated with thinner GM in frontal, parietal, and temporal regions, i.e., AD signature cortical regions, ${ }^{44}$ and is considered a feasible surrogate, but non-specific, marker of neurodegeneration in MCI and AD. ${ }^{45}$ Another finding of our study is that anxiety and depressive symptoms were strongly associated with $\mathrm{nPR}$ in adult-to-old-oldest old subjects. The association of depression with nPR is in agreement with the "vascular depression" hypothesis, ${ }^{46}$ whose central mechanism is the disconnection process of cortical and subcortical regions driven mainly by the disruption of the prefrontal connectivity due to SVD. In $\mathrm{CN}$ older people, depressive symptoms have been associated with WMH. ${ }^{47}$ 
Table 3: Neuropsychological and behavioral performances of adult-to-oldest old NCH subjects $(n=1246)$ with and without nociceptive primitive reflexes (nPR)

\begin{tabular}{|c|c|c|c|c|}
\hline & nPR+ & nPR- & Statistics & $P$ Value \\
\hline & $n=413(33.2)$ & $n=833(66.8)$ & $F$ test or $\chi^{2}$ & \\
\hline \multicolumn{5}{|c|}{ Neuropsychological performances } \\
\hline MMSE, median (IQR) & $29.0(3.0)$ & $29.0(2.0)$ & 14.92 & $<0.001$ \\
\hline \multicolumn{5}{|c|}{$\begin{array}{l}\text { Cognitive domain } z \text { scores, } \\
\text { median (IQR) }\end{array}$} \\
\hline Memory & $-0.13(0.97)$ & $-0.05(1.00)$ & 1.84 & 0.175 \\
\hline Executive function & $-0.11(0.92)$ & $0.02(0.81)$ & 8.99 & 0.003 \\
\hline Attention & $-0.13(1.07)$ & $-0.03(0.99)$ & 6.63 & 0.010 \\
\hline Language & $-0.13(1.21)$ & $0.22(1.04)$ & 77.93 & $<0.001$ \\
\hline Constructional & $0.00(1.42)$ & $0.00(1.90)$ & 0.03 & 0.862 \\
\hline Visuospatial & $-0.01(2.17)$ & $-0.01(2.17)$ & 0.00 & 0.965 \\
\hline \multicolumn{5}{|l|}{ Behavioral performances } \\
\hline Depression & $320(77.5)$ & $417(50.1)$ & 84.79 & $<0.001$ \\
\hline Anxiety & $329(79.7)$ & $444(53.3)$ & 80.35 & $<0.001$ \\
\hline
\end{tabular}

MMSE, Mini-Mental State Examination.

Data presented are number $(\%)$ for categorical, and median (interquartile range, IQR) for continuous data.

Bold values indicate significance at $p \leq 0.05$.

Table 4: Carotid ultrasonography, and imaging findings of adult-to-oldest old NCH subjects $(n=1246)$ with and without nociceptive primitive reflexes (nPR)

\begin{tabular}{|c|c|c|c|c|}
\hline & nPR + & nPR - & Statistics & $P$ Value \\
\hline & $n=413(33.2)$ & $n=833(66.8)$ & $F$ test or $\chi^{2}$ & \\
\hline \multicolumn{5}{|l|}{ Carotid ultrasonography findings } \\
\hline IMT $^{\mathrm{a}}$ & $300(75.8)$ & $277(38.1)$ & 144.01 & $<0.001$ \\
\hline $\operatorname{SICA}^{\mathrm{a}}$ & $34(8.6)$ & $22(3.0)$ & 15.53 & $<0.001$ \\
\hline \multicolumn{5}{|l|}{ Imaging findings } \\
\hline \multicolumn{5}{|l|}{ WMH } \\
\hline Deep/subcortical & $87(21.1)$ & $56(6.7)$ & 54.50 & $<0.001$ \\
\hline Infratentorial & $6(1.5)$ & $6(0.7)$ & 0.88 & 0.348 \\
\hline Basal ganglia & $27(6.5)$ & $13(1.6)$ & 20.44 & $<0.001$ \\
\hline Periventricular & $114(27.6)$ & $47(5.6)$ & 116.40 & $<0.001$ \\
\hline \multicolumn{5}{|l|}{ Lacunes } \\
\hline Deep/subcortical & $78(18.9)$ & $66(7.9)$ & 31.40 & $<0.001$ \\
\hline Infratentorial & $16(3.9)$ & $12(1.4)$ & 6.38 & 0.011 \\
\hline Basal ganglia & $52(12.6)$ & $30(3.6)$ & 34.84 & $<0.001$ \\
\hline \multicolumn{5}{|l|}{ Measures of brain atrophy } \\
\hline Bicaudate ratio & $0.14 \pm 0.02$ & $0.11 \pm 0.02$ & 720.39 & $<0.001$ \\
\hline Lateral ventricles to brain ratio & $2.18 \pm 0.51$ & $1.63 \pm 0.27$ & 626.47 & $<0.001$ \\
\hline
\end{tabular}

${ }^{\mathrm{a}}$ Missing data: IMT, nPR $+=17$; nPR $-=106$; SICA, nPR $+=17$; nPR $-=106$.

IMT, Intimal-medial thickness; SICA, Stenosis of the internal carotid arteries; WMH, White matter hyperintensities.

Data presented are number $(\%)$ for categorical and mean (SD) for continuous data.

Bold values indicate significance at $p \leq 0.05$. 
Table 5: Association between VRF, VD, APOE $\varepsilon 4$ Carriers, IMT, SICA, WMH, lacunes, depression, anxiety, BCr, LVBr, and nociceptive primitive reflexes in adult-to-oldest old NCH subjects $(n=1246)$

\begin{tabular}{|c|c|c|}
\hline & \multicolumn{2}{|c|}{ Odd Ratios $(95 \%$ CI) } \\
\hline & Model 1 & Model 2 \\
\hline Arterial hypertension & $0.91(0.65-1.28)$ & \\
\hline Diabetes mellitus & $0.90(0.61-1.33)$ & \\
\hline Obesity & $1.19(0.87-1.64)$ & \\
\hline COPD & $1.43(0.66-3.17)$ & \\
\hline Ischaemic heart disease & $1.35(0.78-2.33)$ & \\
\hline Atrial fibrillation & $1.32(0.59-3.18)$ & \\
\hline Chronic heart failure & $0.70(0.30-1.62)$ & \\
\hline History of TIA & $1.42(0.77-2.62)$ & \\
\hline Lower limb arteriopathy & $1.36(0.39-5.19)$ & \\
\hline $\mathrm{APOE} \varepsilon 4$ carriers & $1.71(1.21-2.41)$ & $1.73(1.24-2.43)$ \\
\hline IMT & $1.07(0.72-1.57)$ & \\
\hline SICA & $1.33(0.68-2.66)$ & \\
\hline Deep/subcortical WMH & $1.53(0.94-2.48)$ & $1.66(1.07-2.57)$ \\
\hline Basal ganglia WMH & $1.32(0.56-3.20)$ & \\
\hline Periventricular WMH & $2.41(1.48-3.94)$ & $2.66(1.72-4.14)$ \\
\hline Deep/subcortical lacunes & $1.56(0.98-2.50)$ & $1.66(1.06-2.59)$ \\
\hline Infratentorial lacunes & $1.02(0.38-2.81)$ & \\
\hline Basal ganglia lacunes & $1.65(0.91-3.01)$ & $1.73(0.97-3.12)$ \\
\hline Depression & & \\
\hline Anxiety & & \\
\hline Bicaudate ratio & & \\
\hline Lateral ventricles to brain ratio & & \\
\hline
\end{tabular}

VRF, vascular risk factors; VD, vascular diseases; APOE, apolipoprotein E; IMT, intimal-medial thickness; SICA, stenosis of internal carotid artery; $\mathrm{WMH}$, white matter hyperintensities; $\mathrm{BCr}$, bicaudate ratio; $\mathrm{LVBr}$, lateral ventricles to brain ratio; $\mathrm{NCH}$, neurological and cognitively healthy; $\mathrm{CI}$, confidence interval; COPD, chronic obstructive pulmonary disease; TIA, transient ischemic attacks. Model 1 (full) is composed by all the variables found significant by the univariate analysis, and adjusted for age, sex, and education (years). Model 2 (reduced) is obtained by a stepwise model selection procedure with additional adjustments for age, sex, and education (years). Association of depression, anxiety, bicaudate ratio, and lateral ventricles to brain ratio with nPR was estimated using logistic regression analysis separately with adjustments for age, sex, and education (years). Bold values indicate significant associations.

The reappearance later in life of nPR has been related to the loss of the physiological inhibitor control of lower brainstem centres. ${ }^{1}$ Our findings support the hypothesis that their reappearance could be the consequence of the vascular and degenerative damage of the cortical-basal ganglia-thalamo-cortical circuits, causing the disconnection of the cerebral networks subserving this control. In this hypothetical context, caudate atrophy and the likely damage of the internal circuits of BG could have led to an excessive inhibition to its output nuclei with consequent disinhibition of lower brainstem structures.

\section{Limitations of the study}

Some limitations of our study need to be acknowledged. First, among CN subjects aged 50-89 years, different subgroups have been identified on the basis of a various combination of imaging biomarkers of amyloidosis and neurodegeneration of $\mathrm{AD}$ type. ${ }^{10}$ We were unable to perform in our cohort $A \beta$ and tau imaging and to evaluate quantitatively brain regional structural and metabolic abnormalities, so we do not know to which of these subgroups our subjects nPR+ belong to. Second, caudate atrophy and global cerebral atrophy were evaluated using simple linear measures. We are aware of the crudity of the method used, but $\mathrm{BCr}$ and $\mathrm{LVBr}$ are reliable markers of caudate atrophy and global cerebral atrophy, respectively ${ }^{41,45}$ and have the advantage of being inexpensive, not labor-intensive, and easy to use in clinical practice without any technical assistance. Third, we did not evaluate cerebral microbleeds, which are present in $18.6 \%$ of $\mathrm{CN}$ subjects and are associated with age, APOE $\varepsilon 4, \mathrm{~A} \beta$ deposition, lacunes, and severe $\mathrm{WMH}^{48}$ underestimating, probably, the magnitude of SVD in our sample. Lastly, due to the cross-sectional design of our study, we cannot assess causality but only correlations. 
Table 6: Association between glabellar tap, snout reflex, palmomental reflex, and topographical location of WMH scored according to Wahlund scale, lacunes bicaudate ratio, and lateral ventricles to brain ratio in adult-to-oldest old NCH subjects $(n=1246)$

\begin{tabular}{|c|c|c|c|}
\hline & \multicolumn{3}{|c|}{ Odd Ratios $(95 \%$ CI) } \\
\hline & Glabellar tap & Snout reflex & Palmomental reflex \\
\hline \multicolumn{4}{|l|}{ Model 1} \\
\hline \multicolumn{4}{|l|}{ Frontal } \\
\hline WMH & $2.19(1.09-4.26)$ & $0.79(0.36-1.72)$ & $1.41(0.46-3.83)$ \\
\hline Lacunes & $1.03(0.60-1.74)$ & $2.39(1.37-4.21)$ & $1.02(0.46-2.13)$ \\
\hline \multicolumn{4}{|l|}{ Parieto-occipital } \\
\hline WMH & $0.41(0.16-0.97)$ & $0.93(0.37-2.34)$ & $1.90(0.60-6.27)$ \\
\hline Lacunes & $0.90(0.36-2.10)$ & $0.71(0.29-1.70)$ & $1.95(0.49-6.39)$ \\
\hline \multicolumn{4}{|l|}{ Temporal (lateral) } \\
\hline WMH & 3.18 (1.13-9.15) & $3.87(1.15-14.09)$ & $1.26(0.35-4.41)$ \\
\hline Lacunes & $1.50(0.21-6.85)$ & $2.49(0.37-13.01)$ & a \\
\hline \multicolumn{4}{|l|}{ Infratentorial } \\
\hline WMH & $0.33(0.04-1.66)$ & $0.44(0.09-2.30)$ & $0.44(0.05-3.04)$ \\
\hline Lacunes & $1.65(0.45-5.35)$ & $0.70(0.16-3.16)$ & a \\
\hline \multicolumn{4}{|l|}{ Basal ganglia } \\
\hline WMH & $1.15(0.46-2.73)$ & $0.96(0.35-2.60)$ & $0.66(0.19-2.04)$ \\
\hline Lacunes & $1.19(0.64-2.14)$ & $0.75(0.39-1.44)$ & $2.95(1.39-6.06)$ \\
\hline \multicolumn{4}{|l|}{ Model 2} \\
\hline \multicolumn{4}{|l|}{ Frontal } \\
\hline WMH & $2.25(1.16-4.25)$ & & \\
\hline Lacunes & & $2.00(1.24-3.24)$ & \\
\hline \multicolumn{4}{|l|}{ Parieto-occipital } \\
\hline WMH & $0.42(0.17-0.94)$ & & $2.73(1.41-5.14)$ \\
\hline \multicolumn{4}{|l|}{ Lacunes } \\
\hline \multicolumn{4}{|l|}{ Temporal (lateral) } \\
\hline WMH & $3.23(1.21-8.79)$ & $3.53(1.29-10.32)$ & \\
\hline \multicolumn{4}{|l|}{ Lacunes } \\
\hline \multicolumn{4}{|l|}{ Infratentorial } \\
\hline \multicolumn{4}{|l|}{ WMH } \\
\hline \multicolumn{4}{|l|}{ Lacunes } \\
\hline \multicolumn{4}{|l|}{ Basal ganglia } \\
\hline \multicolumn{4}{|l|}{ WMH } \\
\hline Lacunes & & & $2.59(1.27-5.11)$ \\
\hline \multicolumn{4}{|l|}{ Measures of brain atrophy } \\
\hline Bicaudate ratio & $1.38(1.23-1.55)$ & $2.07(1.79-2.40)$ & $1.64(1.29-2.12)$ \\
\hline Lateral ventricles to brain ratio & $1.11(1.06-1.17)$ & $1.26(1.19-1.35)$ & $1.13(1.04-1.23)$ \\
\hline
\end{tabular}

$\mathrm{CI}$, confidence interval; $\mathrm{NCH}$, neurological and cognitively healthy; $\mathrm{WMH}$, white matter hyperintensities.

Model 1 (full) is composed by all the variables found to be significant univariate analysis, and adjusted for age, sex, and education (years). Model 2 (reduced) is obtained by a stepwise model selection procedure with additional adjustments for age, sex, and education (years). Association of BCr and $\mathrm{LVBr}$ with glabellar tap, snout reflex and palmomental reflex was estimated using logistic regression analysis separately with adjustments for age, sex, and education (years).

${ }^{\mathrm{a}}$ Lesions too infrequent for model to converge.

Bold values indicate significant associations. 


\section{Conclusion}

In the modern neurological era, the clinical usefulness of eliciting nPR could seem outdated. However, we have shown that the presence of nPR in adult-to-oldest old NCH individuals is a sign of cortical and subcortical vascular and atrophic changes, and, probably, a warning sign of incipient cognitive decline. Therefore, NCH subjects presenting nPR should manage their VRF/VD rigorously in order to prevent or delay progression of $\mathrm{SVD}$, and future neurological and cognitive disabilities.

\section{Supplementary Material}

To view supplementary material for this article, please visit https://doi.org/10.1017/cjn.2018.388.

\section{ACKNOWLEDGEMENTS}

We gratefully thank all participants and relatives, as well as all neurologists and neuropsychologists who over time collected patients data.

\section{Statement of Authorship}

$\mathrm{CC}$ and $\mathrm{RC}$ were responsible for the study's concept and design, data management, and record linkage.

GS and GC did the statistical analysis. CC, PT, CP, DA, IB, and $\mathrm{RC}$ contributed to the analysis and interpretation of the data.

$\mathrm{CC}$ wrote the paper. All co-authors edited the paper and approved its final version.

\section{Disclosures}

All the authors hereby declare that they have nothing to disclose.

\section{REFERENCES}

1. Delwaide PJ, Dijeux L. Réflexes néonateaux et dyskinésies buccolinguo-faciales dans la démence sénile. Neonatal reflexes and bucco-linguo-facial dyskinesias in senile dementia. L'Actualité en Gérontologie. 1980;6:126-33.

2. Vreeling FW, Houx PJ, Jolles J, Verhey FR. Primitive reflexes in Alzheimer's disease and vascular dementia. J Geriatr Psychiat. 1995;8:111-17.

3. Di Legge S, Di Piero V, Altieri M, et al. Usefulness of primitive reflexes in non-demented cerebrovascular patients in daily clinical practice. Eur Neurol. 2001;45:104-10.

4. Vreeling FW, Verhey FRJ, Houx PJ, Jolles J. Primitive reflexes in Parkinson's disease. J Neurol Neurosurg Ps. 1993;56:1323-26.

5. Tremolizzo L, Susani E, Lunetta C, Corbo M, Ferrarese C, Appollonio I. Primitive reflexes in amyotrophic lateral sclerosis: prevalence and correlates. J Neurol. 2014;261:1196-202.

6. Borroni B, Broli M, Costanzi C, et al. Primitive reflexes evaluation in the clinical assessment of extrapyramidal syndromes. Eur J Neurol. 2006;13:1026-28.

7. Jacobs L, Gossmann MD. Three primitive reflexes in normal adults. Neurology. 1980;30:184-88.

8. IsakovE, Sazbon L, CosteffH, Luz Y, Najenson T. The diagnostic value of three common primitive reflexes. Eur Neurol. 1984;23:17-21.

9. Albert MS, Dekosky ST, Dickson D, et al. The diagnosis of mild cognitive impairment due to Alzheimer's disease: recommendations from the National Institute on Aging and Alzheimer's Association workgroups on diagnostic guidelines for Alzheimer's disease. Alzheimers Dement. 2011;7:270-79.

10. Jack CR Jr, Wiste HJ, Weigand SD, et al. Age-specific population frequencies of cerebral $\beta$-amyloidosis and neurodegeneration among people with normal cognitive function aged 50-89 years: a cross-sectional study. Lancet Neurol. 2014;13:997-1005.

11. Raz N, Lindenberger U, Rodrigue KM, et al. Regional brain changes in aging healthy adults: general trends, individual differences and modifiers. Cereb Cortex. 2005;15:1676-89.

12. Chételat G, Villemagne VL, Villain N, et al. Accelerated cortical atrophy in cognitively normal elderly with high $\beta$-amyloid deposition. Neurology. 2012;78:477-84.

13. Marnane M, Al-Jawadi OO, Mortazavi S, et al. Periventricular hyperintensities are associated with elevated cerebral amyloid. Neurology. 2016;86:535-43.

14. Pantoni L. Cerebral small vessel disease: from pathogenesis and clinical characteristics to therapeutic challenges. Lancet Neurol. 2010;9:689-701.

15. de Leeuw FE, de Groot JC, Achten E, et al. Prevalence of cerebral white matter lesions in elderly people: a population based magnetic resonance imaging study. The Rotterdam scan study. J Neurol Neurosur Ps. 2001;70:9-14.

16. Chen X, Wen W, Anstey KJ, Sachdev PS. Prevalence, incidence and risk factors of lacunar infarcts in a community sample. Neurology. 2009;73:262-72.

17. Duering M, Righart R, Csanadi E, et al. Incident subcortical infarcts induce focal thinning in connected cortical regions. Neurology. 2012;79:2025-28.

18. Lambert C, Narean JS, Benjamin P, Zeestraten E, Barrick TR, Markus HS. Characterising the gray matter correlates of leukoaraiosis in cerebral small vessel disease. Neuroimage Clin. 2015;9: 194-05.

19. Rizvi B, Narkhede A, Last BS, et al. The effect of white matter hyperintensities on cognition is mediated by cortical atrophy. Neurobiol Aging. 2018;64:25-32.

20. Habes M, Erus G, Toledo JB, et al. White matter hyperintensities and imaging patterns of brain ageing in the general population. Brain. 2016;139:1164-79.

21. Alexander GE, DeLong M, Strick PL. Parallel organization of functionally segregated circuits linking basal ganglia and cortex. Ann Rev Neurosci. 1986;9:357-81.

22. Caligiore D, Strick PL, Jörntell H, et al. Consensus paper: towards a systems-level view of cerebellar function: the interplay between cerebellum, basal ganglia, and cortex. Cerebellum. 2017;16: 203-229.

23. Camarda C, Torelli P, Camarda R, Gagliardo C, Monastero R. Isolated, subtle, neurological abnormalities in neurologically and cognitively healthy aging subjects. J Neurol. 2015;262:1328-39.

24. Folstein MF, Folstein SE, McHugh PR. Mini-mental state: a practical method for grading the cognitive state of patients for the clinician. J Psychiat Res. 1975;12:189-98.

25. Katz S, Ford AB, Moskowitz RW, Jackson BA, Jaffe MW. Studies of illness in the aged. The index of ADL: a standardized measure of biological and psychosocial function. J Am Med Assoc. 1963;185:914-19.

26. Lawton MP, Brody EM. Assessment of older people: self-maintaining and instrumental activities of daily living. Gerontologist. 1969;9: 179-86.

27. Morris JC. The clinical dementia rating (CDR): current version and scoring rules. Neurology. 1993;43:2412-14.

28. Hixson JE, Vernier DT. Restriction isotyping of human apolipoproteinE by gene amplification and cleavage with HhaI. J Lipid Res. 1990;31:545-48.

29. Parmelee PA, Thuras PD, Katz IR, Lawton MP. Validation of the cumulative illness rating scale in a geriatric residential population. J Am Geriatr Soc. 1995;43:130-37.

30. Alexopoulos GS, Abrams RC, Young RC, Shamoian CA. Cornell scale for depression in dementia. Biol Psychiat. 1998;23:271-84.

31. Zigmond AS, Snaith RP. The hospital anxiety and depression scale. Acta Psychiat Scand. 1983;67:361-370.

32. Hamilton M. A rating scale for anxiety. J Neurol Neurosurg Ps. 1960;23:6-62.

33. Camarda C, Pipia C, Azzarello D, et al. Vascular risk factors, vascular diseases, and imaging findings in a hospital-based cohort of mild cognitive impairment types. Current Alzheimer Res. 2018;15:679-90. 
34. Wardlaw JM, Smith C, Biessels GJ, et al. Neuroimaging standards for research into small vessel disease and its contribution to ageing and neurodegeneration. Lancet Neurol. 2013;12:822-38.

35. Wahlund LO, Barkhof F, Fazekas F, et al. A new rating scale for age-related white matter changes applicable to MRI and CT. Stroke. 2001;32:1318-22.

36. Fazekas F, Chawluk JB, Alavi A, Hurtig HI, Zimmerman RA. MR signal abnormalities at $1.5 \mathrm{~T}$ in Alzheimer's dementia and normal aging. AJR Am J Neuroradiol. 1987;8:421-426.

37. Akaike $\mathrm{H}$. A new look at the statistical model identification. IEEE T Automat Contr. 1974;19:716-23.

38. Kirk DB. On the numerical approximation of the bivariate normal (tetrachoric) correlation coefficient. Psychometrika. 1973;38:259-68.

39. van Boxtel MPJ, Bosma H, Jolles J, Vreeling FW. Prevalence of primitive reflexes and the relationship with cognitive changes in healthy adults. A report from the Maastricht aging study. J Neurol. 2006;253:935-41.

40. Poggesi A, Gouw A, van der Flier W, et al. Cerebral white matter changes are associated with abnormalities on neurological examination in non-disabled elderly: the LADIS study. J Neurol. 2013;260:1014-21.

41. Doraiswamy PM, Patterson L, Na C, et al. Bicaudate index on magnetic resonance imaging: effects of normal aging. J Geriatr Psych Neur. 1994;7:13-17.
42. Makris N, Kennedy DN, McInerney S, et al. Segmentation of subcomponents within the superior longitudinal fascicle in humans: a quantitative, in vivo, DT-MRI study. Cereb Cortex 2005;15:854-69.

43. Longstreth WT Jr. Brain abnormalities in the elderly: frequency and predictors in the United States (the cardiovascular health study). J. Neural Transm. Suppl. 1998;53:9-16.

44. Madsen SK, Gutman BA, Joshi SH, et al. Mapping ventricular expansion onto cortical gray matter in older adults. Neurobiol Aging. 2014;36(Suppl 1):S32-S41.

45. Nestor SM, Rupsingh R, Borrie M, et al. Ventricular enlargement as a possible measure of Alzheimer's disease progression validated using the Alzheimer's disease neuroimaging initiative database. Brain. 2008;131:2443-54.

46. Alexopoulos GS, Meyers BS, Young RC, Campbell S, Silbersweig D, Charlson M. 'Vascular depression' hypothesis. Arch Gen Psychiat. 1997;54:915-22.

47. O'Brien JT, Firbank MJ, Krishnan MS, et al. White matter hyperintensities rather than lacunar infarcts are associated with depressive symptoms in older people: the LADIS study. Am J Geriat Psychiat. 2006;14:834-41.

48. Yates PA, Desmond PM, Phal PM, et al. Incidence of cerebral microbleeds in preclinical Alzheimer disease. Neurology. 2014;82:1266-73. 